\title{
Currículo como Currere, como Complexidade, como Cosmologia, como Conversa e como Comunidade: contribuições teóricas pós- modernas para a reflexão sobre currículos de matemática no ensino médio
}

\author{
The Curriculum as Currere, as Complexity, as Cosmology, as Conversation, \\ and as a Community: Postmodern Theoretical Contributions to the \\ Reflection on Mathematics Curricula in High School
}

Marcio Antonio da Silva*

\begin{abstract}
Resumo
A transição do paradigma moderno para o pós-moderno representou(a) uma revolução no pensamento com implicações em várias áreas. A passagem da certeza e objetividade para a incerteza e subjetividade é, até hoje, um desafio para pesquisadores. Este artigo apresenta contribuições teóricas pós-modernas para a reflexão sobre currículos de Matemática no Ensino Médio, inspiradas nos cinco C - Currere, Complexidade, Cosmologia, Conversa e Comunidade - de William E. Doll Jr. Com estas considerações, esperamos convencer o leitor sobre a necessidade de dar mais atenção à seleção e organização curricular de temas matemáticos no ensino médio brasileiro.
\end{abstract}

Palavras-chave: Educação Matemática. Currículo. Pós-Modernismo. Ensino Médio.

\begin{abstract}
The transition from the modern to the postmodern paradigm represents a revolution in thought with implications in several areas. The passage of certainty and objectivity to subjectivity and uncertainty is, today, a challenge for researchers. This article presents theoretical contributions to postmodern reflections on mathematics curricula in High School, inspired by the five C's - Currere, Complexity, Cosmology, Conversation, and Community William E. Doll Jr. With these considerations, we hope to convince the reader about the need to pay more attention to the selection and organization of the curriculum of mathematical topics in Brazilian High Schools.
\end{abstract}

Keywords: Mathematics Education. Curriculum. Postmodernism. High School.

\footnotetext{
* Doutor em Educação Matemática pela Pontifícia Universidade Católica de São Paulo (PUC/SP). Professor do Instituto de Matemática, do Programa de Pós-Graduação em Educação Matemática e do Programa de PósGraduação em Educação da Universidade Federal de Mato Grosso do Sul (UFMS). Campo Grande, MS, Brasil. Líder do GPCEM (GP100 - Grupo de Pesquisa Currículo e Educação Matemática). Endereço para correspondência: Cidade Universitária, Caixa Postal 549, CEP: 79070-900, Campo Grande, MS, Brasil. E-mail: marcio.silva@ufms.br. Site: www.gpcem.com.br.
} 


\section{Das definições para as significações}

O século XX foi um tempo marcado pela mudança de concepções da humanidade. No início do século passado, ainda estávamos mergulhados na influência iluminista de progresso, emancipação, verdades absolutas, razão, objetividade e grandes narrativas. $\mathrm{Na}$ segunda metade do século passado, a Pós-Modernidade emerge como um estilo de pensamento que suspeita das explicações totalizantes modernas e desconfia profundamente das objetividades normativas (EAGLETON, 1996).

Nesse movimento, ou nessa forma de pensamento que rompe o suposto progresso científico e suas tão almejadas respostas a todos os problemas da humanidade, as ciências são desestabilizadas e, por intermédio de vários resultados, em vários campos de pesquisa, demonstram-se incompletas, inconsistentes, incertas. Palavras e expressões como complexidade, pensamento complexo e sistemas complexos quebram os paradigmas deterministas de ciências como a Matemática, a Biologia, a Física e a Química.

Complexidade não está ligada à complicação, mas sim a uma curiosa raiz etimológica latina:

\footnotetext{
Existe assim uma relação curiosa entre complexo e perplexo, já que compartilham a mesma raiz. "Perplexo" aparece em 1940 e provém do latim perplexus. Se perplexo significa duvidoso, incerto, confuso, perplexus significava misturado, emaranhado, sinuoso. "Perplexidade" deriva de "perplexo" que significa irresolução, dúvida, confusão (MORIN; CIURANA; MOTTA, 2003, p. 43).
}

Essa perplexidade tem feito com que pesquisadores, engajados na perspectiva pós, rediscutam teorias educacionais, alegando que muitas das teorizações modernas reduziam as discussões a aspectos excessivamente cognitivos ou excessivamente sociais. Na perspectiva pós-moderna, qualquer reducionismo teórico é considerado ingênuo, empobrecendo análises e tornando as conclusões vazias, por serem alicerçadas em aportes reducionistas.

A complexidade e o pós-modernismo têm servido como ricas fontes metafóricas para considerações a respeito da Educação e, mais especificamente, para a área do Currículo. Essas teorizações podem ser inseridas dentro do que Silva (1999a) classificou como teorias póscríticas do currículo.

Dentro dessa perspectiva pós, não há espaço para prescrições oficiais de qualquer natureza, pois essas estão ligadas a características modernas, como o estabelecimento, $a$ priori, de definições e objetivos imutáveis, bem como uma concepção linear de organização curricular. Para Corazza (2010, p. 104-105): 
Um pós-currículo não aceita conviver com nenhum dos currículos oficiais desses governos neoliberais - nem com os seus programas de avaliação -, seja para a educação infantil, seja para o ensino fundamental, médio ou superior, pois constata que tais currículos fundamentam-se no princípio de uma totalizadora identidadediferença nacional. Princípio fictício, fabricado pelo etnocentrismo dos grupos privilegiados e posto em funcionamento pelo aparato disciplinar do Estado. Princípio estratégico, que, embora reconheça os diferentes e fale de suas diferenças, utiliza a tal identidade nacional para tratá-los como desvios ou ameaças. Acima de tudo, princípio obediente, que segue os imperativos globais de administrar a pluralidade, a diversidade e a alteridade, por meio da transformação de cada diferença e de cada diferente em objeto de ação curricular-estatal, a ser corrigido ou eliminado.

Silva (1999a, p. 115) também ressalta algumas características descentralizadoras de um currículo "pós”, ao afirmar que:

[...] parece haver uma incompatibilidade entre o currículo existente e o pósmoderno. O currículo existente é a própria encarnação das características modernas. Ele é linear, sequencial, estático. Sua epistemologia é realista e objetivista. Ele é disciplinar e segmentado. O currículo existente está baseado numa separação rígida entre "alta" cultura e "baixa" cultura, entre conhecimento científico e conhecimento cotidiano. Ele segue fielmente o script das grandes narrativas da ciência, do trabalho capitalista e do estado-nação. No centro do currículo existente está o sujeito racional, centrado e autônomo da Modernidade.

Para corroborar as afirmações desses pesquisadores, os critérios que descreveremos neste artigo não são totalizantes, muito menos servem como padrões a serem consultados para construções de prescrições, mas sim uma intenção de fomentar o debate sobre o que ensinar ou sobre o que não ensinar.

\section{Os cinco C de Doll Jr.}

Em nossa pesquisa de doutoramento (SILVA, 2009) e em artigos publicados posteriormente (PIRES; SILVA, 2011; SILVA M. A., 2012; SILVA, 2013; SILVA; PIRES, 2013) fizemos considerações a respeito dos quatro $\mathrm{R}$ - riqueza, recursão, relações e rigor apresentados por Doll Jr. (1997) como características de um currículo pós-moderno, das quais nos apropriamos para formular critérios específicos para escolha e organização de conteúdos matemáticos para o Ensino Médio.

Nesse artigo, trazemos outras contribuições teóricas curriculares de William E. Doll Jr., também buscando adaptá-las à Educação Matemática. Pretendemos que essas contribuições, assim como os quatro R, sirvam para fomentar a discussão sobre o que seriam características ou traços de um currículo pós-moderno. 
Para isso, selecionamos o texto (DOLL JR., 2002) no qual Doll Jr. apresenta os cinco C de currículo como currere, como complexidade, como cosmologia, como conversação e como comunidade.

Nossa intenção, como já afirmamos, não é prescrever orientações, mas sim problematizar algumas ideias hegemônicas que parecem indiscutíveis, até mesmo no campo científico da Educação Matemática.

\subsection{Currículo como currere}

$\mathrm{O}$ primeiro dos cinco $\mathrm{C}$ descritos por Doll Jr. (2002) remonta à reflexão sobre a origem etimológica da palavra currículo, realizada por Pinar e Grumet (1976):

Currere significa "correr". Especificamente, isso significa percorrer um percurso, um percurso fechado, como o usado por carros no circus maximus. Assim, ao falar de currículo, é possível focar o percurso (como substantivo) como um objeto material ou sobre o percorrer o percurso (um verbo), como uma experiência pessoal. Desde a época de Ramus e Comenius, consideramos currículo quase exclusivamente em termos de percurso para ser executado, e não em termos de experiência pessoal do corredor $^{1}$ (DOLL JR., 2002, p. 43, tradução nossa).

Essas considerações trazem implicações importantes para as concepções que temos sobre o currículo. Por exemplo, se tomarmos as cinco dimensões curriculares elencadas por Sacristán e Pérez-Gómez (1998): (i) o currículo prescrito e regulamentado, (ii) o currículo planejado para professores e alunos, (iii) o currículo organizado no contexto de uma escola, (iv) o currículo em ação, (v) o currículo avaliado; podemos afirmar que ideias modernistas sobre currículo (currere como substantivo) tendem a supervalorizar as prescrições, os planejamentos, as organizações e as avaliações, todas essas dimensões influenciando e determinando a ação. Por outro lado, numa perspectiva pós-moderna, considerando currere como verbo, o protagonismo é da ação.

É importante salientar que a concepção pós-moderna de currículo não acaba com a necessidade de estabelecer objetivos, como alguma interpretação radical poderia concluir. Para que o corredor possa exercer sua ação (correr) precisa de um percurso para fazê-lo, ainda que hipotético. Entendemos que a crítica central de William Pinar e Madeleine Grumet sobre

\footnotetext{
${ }^{1}$ Currere means "to run". Specifically it means to run a course, a closed course such as that used by chariots in the circus maximus. Hence in talking of curriculum, it is possible to focus on the course (a noun) as a material object or on the running of the course (a verb) as a personal experience. Since the Ramus and Comenius, we have considered curriculum almost exclusively in terms of the course to be run, not in terms of the personal experience of running.
} 
a necessidade de compreender currere como verbo é a inexistência de reflexões sobre a perspectiva do corredor, levando em conta apenas o ponto de vista do construtor do percurso.

Isso nos leva a constatar que, atualmente, a perspectiva moderna de currere domina as regulações educativas. Reflete-se muito sobre a necessidade de se instituir orientações curriculares que, embora não sejam construídas com o objetivo de estabelecer regras categóricas, são interpretadas como tal. Também se valoriza muito a importância dos diferentes materiais que apresentam o currículo, como livros didáticos, materiais manipuláveis, recursos digitais, entre outros. Por fim, a avaliação, principalmente as feitas em larga escala, medem a eficácia de execução do projeto, sem levar em conta as especificidades dos participantes protagonistas: os estudantes.

$\mathrm{Na}$ perspectiva atual, utilizando a metáfora etimológica de currere, é como se colocássemos pessoas sedentárias e atletas de alto rendimento na mesma pista para correr uma prova de cem metros rasos e transferíssemos nossa confiança de que o bom desempenho de ambos os grupos poderia ser justificado pela qualidade de planejamento e construção da pista na qual eles correrão. Para os que fossem reprovados, bastaria repetir a corrida várias vezes até que os objetivos fossem contemplados satisfatoriamente.

Ora, essa perspectiva ignora as condições prévias e o próprio reconhecimento das diferentes características das pessoas que correm. Ou seja, o quanto podem evoluir e se a mesma pista é adequada para todos. Em suma, desconhece o significado que cada participante atribui ao processo no qual está inserido e obrigado a seguir.

Os currículos de Matemática do Ensino Médio no Brasil ignoram a variedade de corredores que temos. A pista é planejada meticulosamente pensando em uma formação unívoca. Pouco dos conhecimentos e experiências prévias dos participantes é levado em conta no processo. Os temas abordados são incontestáveis, ignorando as perspectivas e motivações trazidas pelos estudantes. Os professores são alinhados numa perspectiva performática (NETO; SILVA, 2013), buscando bons resultados em avaliações em larga escala, pouco considerando as especificidades da comunidade na qual trabalham, muito menos as demandas peculiares de seus alunos.

Considerar a perspectiva do corredor implica uma experiência autorreflexiva dos atores do processo. Pinar e Grumet (1976, p. 54, tradução nossa) expressam isso por 
intermédio de uma metáfora: "eu vejo que os meus pensamentos são como bolhas no fundo de um lago, e eu estou na superfície, e elas expressam... a estrutura profunda do meu ser ${ }^{2}$ ".

Isso requer dos formadores de professores de Matemática uma postura de instigar a autorreflexão nos futuros professores. Apresenta também a necessidade de mudar os rumos durante todo o processo, considerando as demandas específicas. Ao interpretarmos currere como verbo, nos posicionamos a favor da construção de currículos personalizados que valorizem a experiência do corredor e não apenas a beleza do percurso, pois essa beleza pode estar apenas no olhar de quem planejou as prescrições, e não no olhar do professor, muito menos do aluno.

\subsection{Currículo como complexidade}

Para Doll Jr. (2002), a complexidade ainda é uma perspectiva científica ignorada pelos atores que constroem e participam das dinâmicas curriculares.

Segundo esse pesquisador, desde as classificações e ordenações disciplinares de Peter Ramus, no século XVI, passando pelos princípios fundantes de elaborações curriculares formulados por Ralph Tyler, na primeira metade do século passado, e até os dias de hoje, estamos impregnados pelo ideal modernista da simplificação.

A simplificação e ordenação que visa o progresso e o avanço científico repousam, em parte, na ilusão da linearidade e na ignorância da influência de relações mais complexas sobre esse sistema.

Como já dissemos no início deste artigo, resultados científicos colocaram em dúvida as verdades absolutas que atingiram seu auge no século XX. Para Morin (2007) existiam três grandes pilares sobre os quais a certeza científica repousava: (i) a ordem, a regularidade, a constância e, sobretudo, o determinismo absoluto; (ii) a separabilidade, a qual garantia a possibilidade de conhecer um objeto ou um corpo, separando-o do seu meio de origem para examiná-lo num meio artificial; (iii) o valor da prova absoluta fornecida pela indução e pela dedução, e pelos três princípios aristotélicos que estabelecem a unicidade da identidade e a recusa da contradição.

Morin (2007, p. 63-64) sintetiza os desafios da complexidade na contemporaneidade:

[...] o desafio da complexidade reside no duplo desafio da religação e da incerteza. É preciso religar o que era considerado como separado. Ao mesmo tempo, é preciso

\footnotetext{
${ }^{2}$ I see that my thoughts are like bubbles from the bottom of a pond, and I am on the surface; and they express... the deep structure of my being.
} 
aprender a fazer com que as certezas interajam com a incerteza. O conhecimento é, com efeito, uma viagem que se efetiva num oceano de incerteza salpicado de arquipélagos de certeza. Não resta dúvida que nossa lógica nos é indispensável para verificar e controlar, mas, ao fim e ao cabo, o pensamento acaba por operar transgressões nela. A racionalidade não se reduz à lógica, mas a utiliza como um instrumento. A ciência reconheceu oficiosamente este desafio da complexidade que hoje penetra no conhecimento científico, embora não seja ainda reconhecido oficialmente.

Considerar a incerteza e a necessidade de religação implica repensar o papel da Matemática nos currículos do Ensino Médio, deixando para trás a visão de ciência fechada, infalível e completa. Seria recomendável que o professor a apresentasse como um conjunto de conhecimentos que se inter-relacionam com outras ciências, inclusive com as humanidades, e pode ser vislumbrada também por sua falibilidade e incompletude.

Davis e Simmt (2003), ao discutirem sistemas complexos de aprendizagem $^{3}$ e as contribuições da ciência da complexidade para a Educação Matemática, elencam cinco características que deveriam ser levadas em conta nas aulas de Matemática, para que esses contextos dinâmicos da complexidade pudessem emergir: (i) necessidade de desenvolver atividades em sala de aula que possam ser adaptadas pelos alunos aos seus entendimentos e interpretações particulares; (ii) importância de experiências compartilhadas e construção de padrões de engajamento; (iii) necessidade de reconsideração dos planejamentos de aulas, menos em termos de prescrições e itinerários e mais como experiências de pensamento; (iv) importância da definição de limites e regras, ou seja, pensar mais nas restrições ou proscrições que nas prescrições; (v) atenção às interações e às maneiras com as quais as ideias podem ser representadas e justapostas.

A essência dessas características reside na necessidade e dependência das interações estudante-estudante e professor-estudante. A sala de aula de Matemática pode ser compreendida como um sistema complexo, caótico, em permanente interação com o ambiente do qual faz parte. Nesse contexto, a atividade coletiva é sempre mais rica que a soma das percepções individuais. O sujeito só se constitui pelas interações com o outro (SILVA, 2001).

Para Doll Jr. (2002, p. 46, tradução nossa), a ideia central da complexidade é:

[...] que a natureza, a vida, a organização, tudo ocorre quando há um nível suficiente, mas simples de interações complexas, e que, a partir dessas interações complexamente simples, novos e mais complexos níveis da natureza, vida e organização surgem. O processo pode ser sempre constante. Olhar o currículo - não como um curso linear a ser executado -, mas como uma rede complexa e dinâmica das interações, que evolui naturalmente para formas variadas e interligadas, é uma

\footnotetext{
${ }^{3}$ Complex learning systems.
} 
tarefa formidável que vai exigir visão e perseverança. É uma tarefa para a qual curricularistas não têm praticamente nenhuma experiência ${ }^{4}$.

Na perspectiva da complexidade, a aplicação de modelos, incluindo sequências de atividades, projetos, materiais instrucionais, não produz resultados similares. Pelo contrário, a incerteza domina o cenário, sendo fundamental que o professor construa uma espécie de sensibilidade para realizar as leituras necessárias dos sistemas complexos que se modificam constantemente, fazendo os ajustes e os replanejamentos necessários.

Ao mesmo tempo, é importante considerar a Matemática como parte de um panorama mais amplo. Por esse aspecto, vale ressaltar a necessidade de valorizar a inter e, sobretudo, a transdisciplinaridade como organização curricular mais adequada à perspectiva pós-moderna.

Especificamente no Ensino Médio, seria recomendável que o próprio percurso fosse planejado com várias alternativas, para que os jovens tivessem opções variadas, que se relacionassem às mais diversas demandas. Considerando a complexidade, os estudantes também deveriam ter a opção de mudança ao longo do processo. Essa mudança, tomando-se um pensamento moderno como referência, muitas vezes é ligada à concepção de erro ou de reinício de uma trajetória. Na perspectiva pós-moderna, a mudança é tomada como algo natural e representa apenas uma, de várias possibilidades de escolha.

\subsection{Currículo como Cosmologia}

Doll Jr. (2002) ressalta que, atualmente, a Cosmologia é quase que exclusivamente associada à ciência que estuda a origem e o destino do universo. Para ele, essa concepção científica está enraizada nos fundamentos do Modernismo, pautada na compreensão instantânea, como se quisesse revelar fotografias que trazem, com grande precisão, as posições relativas interplanetárias e interestelares.

O pesquisador cita Alfred Whitehead como um visionário pós-moderno para a sua época (1861 - 1947), pois acreditava que a visão moderna de Cosmologia precisaria ser substituída por uma nova Cosmologia que descreva o universo em termos dos seus

\footnotetext{
${ }^{4}[\ldots]$ that nature, life, organization all occur when there is a sufficient but simple level of complex interactions, and that from these complexly simple interactions new and more complex levels of nature, life, organization arise. The process may be forever ongoing. Looking at curriculum - not as a linear course to be run - but as a complex and dynamic web of interactions evolving naturally into more varied interconnected forms is a formidable task that will require vision and perseverance. It is a task for which curricularists have virtually no experience.
} 
movimentos dinâmicos, não em termos das partículas rígidas, maciças e impenetráveis da concepção newtoniana.

Essa metáfora das duas visões de Cosmologia - uma delas estática, precisa, unificadora; e a outra dinâmica, incerta e múltipla - serve de inspiração para considerações que Doll Jr. (2002), citando Whitehead, faz sobre a escola e a pedagogia: "não ensine assuntos demais [...] aquilo que você ensinar, ensine cuidadosamente [...] faça com que as ideias introduzidas na educação de uma criança sejam poucas e importantes, e faça com que elas sejam lançadas em todas as combinações possíveis" (WHITEHEAD, 1929 apud DOLL JR., 1997, p. 158).

Ainda sobre a visão curricular de Whitehead, Doll Jr. (2002, p. 47-48, tradução nossa) afirma que, para esse matemático e filósofo britânico:

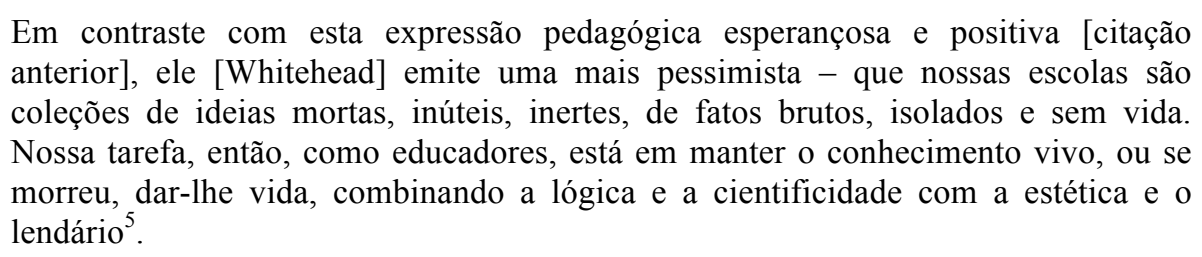

Essa valorização das lendas, dos mitos e da variedade de histórias, ainda que fictícias, é também uma característica que Doll Jr. (2002) reitera como sendo parte de uma perspectiva pós-moderna. Paradoxalmente, isso era feito pelos povos antigos, como os gregos, que tanto valorizavam a mitificação do ser, a hibridação entre o humano e o divino, entre a realidade e a fantasia.

A nosso ver, essas considerações trazem duas implicações que coadunam com as perspectivas curriculares pós-modernas: a valorização do local, em detrimento do global, e a superação das metanarrativas, e a consequente valorização das narrativas.

O que chamamos de valorização do local é considerar, no currículo, a cultura, as histórias, os costumes, os objetivos, as necessidades e os anseios da comunidade na qual a escola está inserida. Essa postura descentralizadora tem como consequência imediata o desprendimento de orientações curriculares universais, quer sejam nacionais, estaduais e até municipais. Cada escola, cada sala de aula, pode ser vislumbrada como uma comunidade específica e, para que os ideais de Whitehead sejam contemplados, cada indivíduo deveria ser ouvido, tornando-se um participante ativo na construção curricular.

\footnotetext{
${ }^{5}$ In contrast to this hopeful and positive pedagogic expression, he issues a more pessimistic one - that our schools are collections of dead, useless, inert ideas, of brute facts, isolated and lifeless. our task then as educators is in keeping knowledge alive, or if dead to give it life by combining the logical and scientific with the aesthetic and storied.
} 
Para D’Ambrosio (1997, p. 82-83):

\begin{abstract}
A busca de uma sociedade integrada no nosso entorno familiar - onde está o outro mais imediato -, no nosso entorno comunitário - a nossa tribo -, no nosso entorno nacional - o nosso país -, são etapas necessárias para se chegar à integração da humanidade como um todo - o nosso planeta. Então poderemos nos situar num contexto mais amplo, transcender nossa existência tão efêmera, avaliar nossa dimensão como indivíduos na realidade cósmica. Espera-se que a arrogância, a inveja e a prepotência cedam lugar ao respeito pelo diferente, à solidariedade com o outro e à cooperação na preservação do patrimônio natural e cultural comuns.
\end{abstract}

Nesse excerto, o autor permite que possamos olhar a perspectiva curricular por um ponto de vista diferente do caminho tradicionalmente percorrido pelo currículo, ou seja, do global para o local, mas sim do local para o global. Nesse cenário, não há prescrições universais que devam ser adaptadas aos contextos particulares, mas sim um conjunto de demandas específicas de várias comunidades que podem determinar um panorama coletivo híbrido, polimorfo e descentralizado.

Outra consequência da assunção da metáfora da Cosmologia é o adeus às metanarrativas. Esse é um ponto particularmente incômodo, sobretudo para pesquisadores da Educação que, muitas vezes, sustentam seus aportes teóricos em alicerces fundamentados em metanarrativas. Para Silva (2011, p. 258):

Possivelmente nenhum questionamento pós-modernista tenha atingido mais seriamente a educação que o desfechado contra as metanarrativas. O campo educacional é um campo minado de metanarrativas. Impossível andar nele sem esbarrar em uma. Usamos metanarrativas para construir teorias filosóficas da educação; utilizamos metanarrativas para analisar sociológica e politicamente a educação; nossos currículos educacionais deixariam de existir sem as metanarrativas - metanarrativas históricas, sociais, filosóficas, religiosas, científicas. O golpe contra as metanarrativas é, portanto, um golpe contra o edifício teórico educacional, seja aquele tradicionalmente construído, seja o da teorização crítica.

Silva (2011, p. 259) também argumenta sobre o porquê de desconsiderar as metanarrativas educacionais e o que há por trás dos discursos totalizantes:

Em termos de teoria, as metanarrativas educacionais têm servido frequentemente apenas para que certos grupos imponham suas visões particulares, disfarçadas como universais, às de outros grupos. As metanarrativas com frequência impedem a discussão pública e aberta ao suprimirem antecipadamente perspectivas que se lhes opõem. Por outro lado, em termos mais curriculares, as metanarrativas têm servido apenas para justificar a exclusão do currículo de outras narrativas que não se encaixam nos pressupostos e dogmas da narrativa mestra que está no comando.

Como alternativa à superação das metanarrativas, Silva, T. T. (2012, p. 199) propõe o reconhecimento da variedade de narrativas para romper as hegemonias dominantes:

Reconhecer o currículo como narrativa e reconhecer o currículo como constituído de múltiplas narrativas significa colocar a possibilidade de desconstruí-las como narrativas preferidas, como narrativas dominantes. Significa poder romper a trama que liga as narrativas dominantes, as formas dominantes de contar histórias, à produção de identidades e subjetividades sociais hegemônicas. As narrativas do currículo devem ser desconstruídas como estruturas que fecham possibilidades 
alternativas de leitura, que fecham as possibilidades de construção de identidades alternativas. Mas as narrativas podem também ser vistas como textos abertos, como histórias que podem ser invertidas, subvertidas, parodiadas, para contar histórias diferentes, plurais, múltiplas, histórias que se abram para a produção de identidades e subjetividades contra-hegemônicas, de oposição.

Apenas para exemplificar uma história hegemônica presente no ensino da Matemática, mostramos em Silva, M. A. (2012) que, em geral, a história apresentada nos livros clássicos de História da Matemática é protagonizada por homens brancos, europeus e brancos, ignorando as outras histórias da Matemática, como a história das mulheres, dos homossexuais, dos negros, dos africanos, dos asiáticos, dos americanos (incluindo brasileiros), entre outras narrativas abafadas pelo discurso hegemônico vigente.

Voltando à metáfora cosmológica e os ideais de Whitehead, seria recomendável superarmos as metanarrativas e ouvirmos as narrativas dos indivíduos marginalizados, possivelmente as histórias dos próprios estudantes que temos em nossas salas de aula.

\subsection{Currículo como conversa}

Contrastando com a magnitude cosmológica do critério anterior, o currículo como conversa, tal como nos apresenta Doll Jr. (2002), é concebido mais especificamente para as relações interpessoais.

Doll Jr. (2002) cita o apelo feito por William Pinar e Richard Rorty para que as teorias curriculares sejam menos teóricas e cientificistas e mais humanizadas. Para isso, eles convidam a todos para que exercitem a conversação como forma de estreitar laços de convivência.

De acordo com o dicionário Oxford, a origem etimológica latina de conversar é conversare e significa transformar-se. Já o dicionário Houaiss, apresenta a etimologia de conversação como sendo conversatio e está relacionado à convivência. Transformação e convivência são palavras repletas de significados para os educadores.

Doll Jr. (2002, p. 49, tradução nossa) pondera que o vocábulo conversa tem a mesma raiz da palavra convergência. Sobre isso, afirma que:

[...] há uma ligação histórica entre conversa e convergência - é através de uma conversa pessoal que nos transformamos e convergimos ou nos unimos. Na conversa depositamos nossas esperanças, tanto para a convergência, quanto para a transformação: nos transformamos, assim como os nossos pontos de vista diferentes 
convergem para o que atualmente está além de nós, e a situação se altera ou se transforma à medida que passamos pelo processo de convergência ${ }^{6}$.

Essa convergência só é possível pelo exercício da alteridade, e não da tolerância, pois tolerar implica apenas e tão somente suportar, mantendo-nos da forma como somos. A alteridade está ligada à transformação, ao aprendizado como ser humano, por intermédio das diferenças. Nessa perspectiva, mais do que reconhecer as diferenças, somos levados a construirmos nossas próprias identidades a partir das distinções, negando a existência de um $e u$ independente dos outros.

Doll. Jr. (2002, p. 50, tradução nossa) reflete acerca dos objetivos dessa tomada de consciência sobre a alteridade:

\begin{abstract}
Nos níveis curriculares e instrucionais, o objetivo é fazer com que professores e estudantes tenham respeito, honra, compreendam a sua própria natureza humana, a "alteridade" de cada outro que constitui cada um, bem como a "alteridade" dos textos estudados e as formas de pensar, inscritas neles. Para este fim (integrado, ainda que multifacetado), podemos incentivar os professores a respeitarem a alteridade humana de seus alunos (não importa a idade, sexo, raça, religião), e encorajar os professores a incentivarem os alunos a terem "conversas" com a linguagem das artes, da matemática, da ciência e com textos de ciências sociais e os conteúdos deles ${ }^{7}$.
\end{abstract}

Outra dimensão do currículo como conversa está ligada à riqueza de significações produzidas. Isso requer a compreensão da conversa como fluxo de palavras e significados, como o fluxo turbulento das águas de um rio ou o fluxo do vento, os quais não possuem padrões previsíveis, simplesmente fluem. Para Trueit (2005, p. 78, tradução nossa), “a ação da conversa é que ela joga com significados e relações, transgride, narra e questiona, e assim começa a reconhecer e desafiar os limites da certeza" $"$.

Essa perspectiva vai ao encontro do conceito de jogos de linguagem de Wittgenstein ou das práticas de significação, no campo dos estudos culturais:

Os significados organizam-se em sistemas, em estruturas, em relações. Esses sistemas, essas estruturas, essas relações, por sua vez, apresentam-se, organizam-se como marcas linguísticas materiais, como tramas, como redes de significantes, como tecidos de signos, como textos, enfim. Do ponto de vista analítico, quando nos aproximamos desses textos para destacar precisamente sua dimensão de prática de

\footnotetext{
${ }^{6}[\ldots]$ there is a historical binding between conversation and convergence - through personal conversation we turn ourselves about and converge or come together. In conversation lie our hopes for both convergence and transformation: we become transformed as our differing views converge on that which presently is beyond us, and the situation itself changes or becomes transformed as we go through the convergence process.

7 At the curricular and instructional levels, the goal here is to have teachers and students respect, honor, understand their own humanness, the 'otherness' of each other of which the self is made as well as the 'otherness' of the texts studied and the ways of thinking inscribed in them. Toward this (integrated yet multifaceted) and, we might encourage teachers to respect the human otherness of their students (no matter the age, gender, race, religion) and for the teachers to encourage students to have 'conversations' with language arts, mathematics, science and social science texts and the contents therein.

${ }^{8}$ The action of conversation is that it plays with meaning and relations, transgresses, narrates and questions, and in so doing begins to recognize and then challenge the bounds of certainty.
} 
significação, para flagrar as marcas de duas condições de produção, para tornar visíveis os artifícios de sua construção, para 'decifrar' os códigos e as convenções pelas quais esses significados particulares foram produzidos, para descrever seus efeitos de sentido, passamos a vê-los como discurso e os atos, as atividades, o trabalho de sua produção como prática discursiva (SILVA, T. T., 1999b, p. 18-19).

Conceber o currículo como conversa é abrir-se para a incerteza e a fluidez dos jogos de linguagem envolvidos em uma sala de aula de Matemática do Ensino Médio. É ter consciência da necessidade de ouvir, e não só falar. Para o professor de Matemática, é atentarse às diferentes linguagens com as quais os alunos se expressam, não só a escrita, como tradicionalmente os estudantes são avaliados, mas também pela oralidade, gestualidade, simbologia (matemática e não matemática), entre outras.

A própria Matemática produz variadas significações que devem ser reconhecidas em sua pluralidade de formas de expressão e conhecimentos.

Seria recomendável que o professor, em sua sala de aula, criasse um ambiente favorável à conversação, não como um expert, mas como um agente mediador das demandas variadas que emergem dos estudantes, buscando convergências, mas, sobretudo, desvelando a variedade de matemáticas existentes, utilizando-as, comparando-as e desmascarando-as.

\subsection{Currículo como comunidade}

Doll Jr. (2002) se refere a este critério como o mais importante dos cinco C, pois serve como amálgama dos outros quatro.

Quando menciona comunidade, Doll Jr. reporta-se à comunidade humana, mas ressalta que esta não é independente das comunidades ecológicas e cosmológicas maiores:

Bowers (1995) tem uma metáfora boa para isso, quando diz que as comunidades são
'aninhadas' umas dentro das outras - o ser humano dentro do cultural, o cultural
dentro do ecológico, e, eu acrescentaria, o ecológico ou natural dentro do
cosmológico. Temos de perceber o nosso lugar e papel dentro desta hierarquia
aninhada para que não adotemos a arrogância do pensamento iluminista e
assumamos tacitamente a consciência humana como sendo o epítome de toda a
consciência ${ }^{9}$ (DOLL JR., 2002, p. 51-52, tradução nossa).

Acrescentaríamos às considerações de Doll Jr., a interdependência das comunidades citadas por ele com as comunidades menores, por exemplo, a comunidade de professores de

\footnotetext{
${ }^{9}$ Bowers has a nice metaphorical phrase for this when he says that communities are 'nested' within one another - the human within the cultural, the cultural within the ecological, and, I would add, the ecological or natural within the cosmological. We must realize our place and role within this nested hierarchy lest we adopt the arrogance of Enlightenment thought and tacitly assumes human consciousness to be the epitome of all consciousness.
} 
Matemática, a comunidade de estudantes do Ensino Médio, a comunidade dos integrantes de uma sala de aula, a comunidade formada pelos moradores que residem no entorno da escola.

Isso requer de todos, ao mesmo tempo, cuidado e crítica para que, por um lado não caiamos numa individualidade exacerbada, gerando um etnocentrismo (LARAIA, 2006) inaceitável; e, por outro lado, sempre tenhamos uma consciência reflexiva crítica sobre as necessidades proeminentes das comunidades nas quais estamos inseridos (incluindo a própria humanidade).

Nessa perspectiva, a força criativa do ser humano, aliada à capacidade de conversação e convergência, pode nos impulsionar a pensar, tanto em questões que nos diferenciam, constituindo nossas identidades - como raça, etnia, credo e gênero -, quanto em problemas ecológicos, cosmológicos e globais que são comuns a todos os seres humanos.

Para os professores de Matemática e para os formadores de professores de Matemática é importante incluir discussões humanísticas que, normalmente, são deixadas para um segundo plano de interesse ou apenas contempladas do ponto de vista educacional, em geral, preocupando-se com questões sobre como ensinar ou reduzindo-se ao estudo de aspectos cognitivos dos estudantes.

Pouca ou nenhuma atenção tem sido dada à formação (inicial e em serviço) do professor em ciências humanas. Esse cenário pós que se delineia como uma demanda necessária para a educação do novo milênio requer uma leitura do mundo, por parte do professor, que só é possível pelo estudo aprofundado de questões ligadas à Sociologia, à Antropologia, aos Estudos Culturais, à Ecologia, entre outros campos de conhecimentos.

Isso também exige uma formação trans que requer dos professores uma compreensão, ainda que geral, das contribuições contemporâneas de várias ciências, além da compreensão temporal e dos níveis macro e micro desses fenômenos. Davis (2008) expõe essa complexidade por intermédio de uma figura elucidativa: 


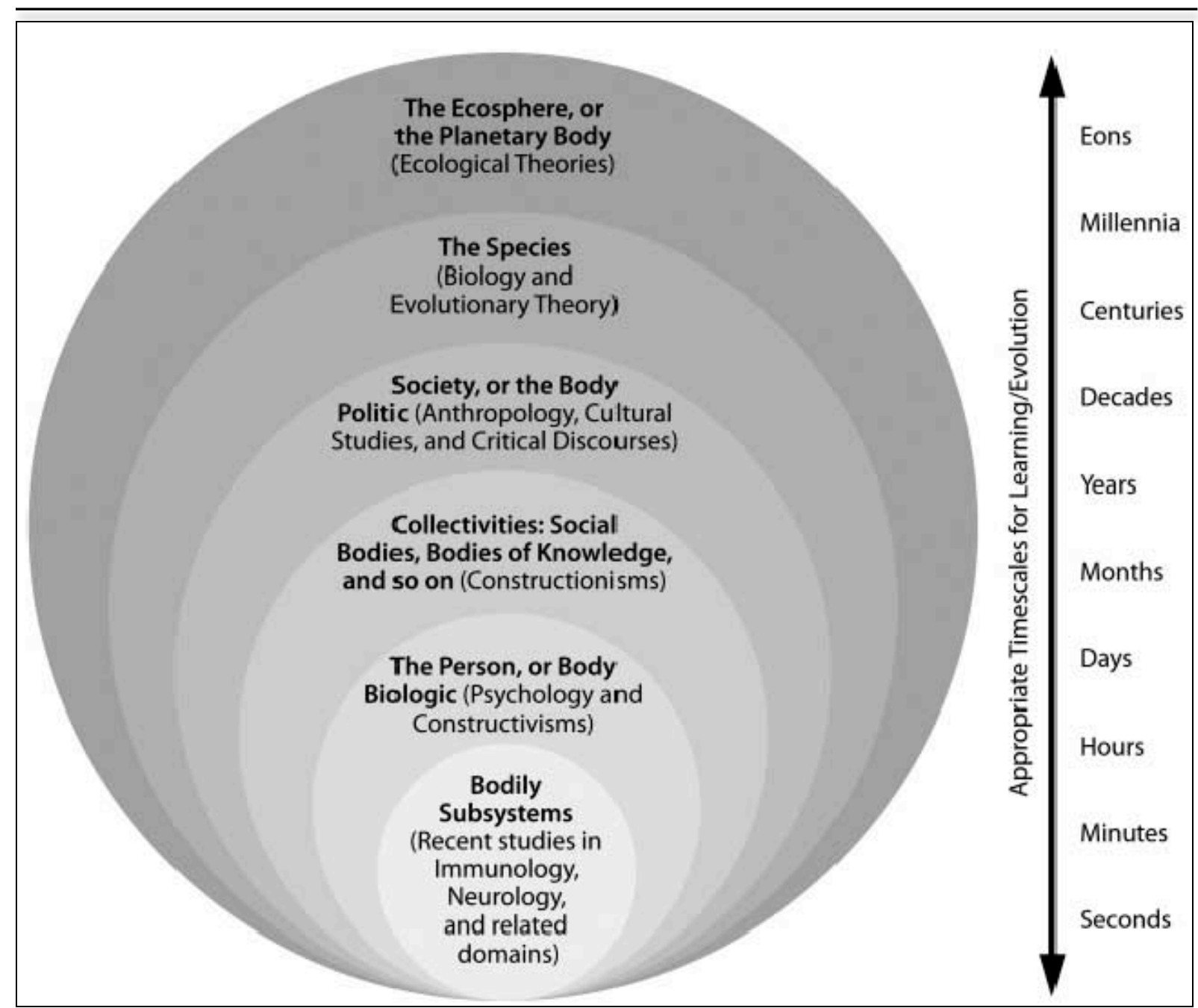

Figura 1 - Alguns dos sistemas aninhados que são de interesse para os pesquisadores educacionais. Fonte: Davis (2008, p. 56).

Esse diagrama suscita várias reflexões a respeito não só dos currículos de Matemática no Ensino Médio, mas também relativas às pesquisas e à formação de professores. Uma das possíveis reflexões diz respeito à escala temporal relativa à aprendizagem e evolução: será que não estamos nos preocupando demasiadamente com o imediatismo, em detrimento das discussões coletivas que requerem mudanças mais lentas e graduais?

Também nos faz compreender a amplitude e temporalidade das comunidades científicas nas quais estamos inseridos, muitas delas, incluindo algumas comunidades de pesquisa em Educação Matemática, têm poucas contribuições nos níveis da sociedade, das espécies e da ecosfera.

A nosso ver, em geral, a Matemática ainda é vista como uma ciência neutra, desconsiderando e ignorando os fatores sociais, políticos e culturais que influenciam todos nós. Talvez por isso, a pesquisa em Educação Matemática pouco discute questões anteriores ao como ensinar ou ao como aprender, tais como: Por que ensinar? O que ensinar? Por que 
este modelo de escola e não outro? Por que este modelo disciplinar e não outro? Por que precisamos de modelos?

Olhar o currículo como comunidade é vislumbrar, simultaneamente, o macro e o micro, não como um binarismo, e sim na dinamicidade do olhar que foca um ponto, mas que, por intermédio da visão periférica, não perde a noção do todo, nem a capacidade de identificar padrões, movimentos e fluxos.

Isso requer percorrer caminhos opostos aos das especializações do conhecimento e das disciplinarizações das ciências. Exige, de cada um de nós, um interesse pelos problemas dos outros, assim como nos interessamos pelos nossos próprios problemas. Longe de ser uma afirmação dogmática, a frase anterior nos remete à compreensão e à consciência, que cada um de nós deveria ter, sobre a complexidade de ligações que a nossa comunidade de seres humanos possui, onde cada crise nas ligações provoca reverberações em todo o sistema.

No entanto, há que se ter cuidado para não promover um ideal romântico fantasiado pelos teóricos críticos, no qual a sociedade justa e igualitária seria possível por intermédio da tomada de consciência, por parte dos oprimidos, da opressão de uma classe social dominante. Na perspectiva pós, toda igualdade é utópica, e as diferenças não só são necessárias, como nos constituem como sujeitos. Contudo, esse reconhecimento não deveria resultar numa arrogância egocêntrica.

\section{Considerações finais ou novas considerações iniciais: fim ou recomeço?}

Ao concluirmos este artigo, não temos apenas a intenção de sintetizar o que já foi dito, como tradicionalmente se faz nos papers publicados em periódicos científicos. Tentaremos encarnar o discurso pós, trazendo outros questionamentos que podem fomentar novas discussões e contribuições.

Também fugindo das clássicas formas de apresentação de conclusões, iniciaremos pelo compartilhamento de nossas angústias ao escrevermos esse texto. O que não deu certo? O que está incompleto? Por quê? Reconhecemos que, uma das fragilidades das considerações feitas, foi refletir sobre a Matemática e, ainda mais especificamente, sobre a Matemática no Ensino Médio nesse cenário pós-moderno. Em outros artigos publicados por nós sobre os quatro $\mathrm{R}$, já referenciados neste, conseguimos relacionar possibilidades para o professor de Matemática trabalhar no Ensino Médio, mas neste ensaio teórico, sentimos uma enorme 
dificuldade para realizar tal exercício de adaptação (das teorias curriculares pós-modernas para as práticas da sala de aula de Matemática do Ensino Médio).

No entanto, nos sentimos reconfortados por dois detalhes que parecem explicar essa aparente dificuldade que encontramos: o primeiro refere-se ao intervalo de quase dez anos entre a escrita original dos quatro R (DOLL JR., 1993) e a elaboração das considerações sobre os cinco C; o segundo remete-nos ao esquema construído por Davis (2008), apresentado na Figura 1, no qual se delineia a variedade de abordagens de pesquisa. Temos um forte pressuposto relacionado à possibilidade de, tanto as considerações de Doll Jr., quanto as nossas, tenham se deslocado, tomando-se o diagrama de Davis como referência, para os sistemas mais externos. Esse olhar mais voltado ao cosmos que ao indivíduo e mais voltado às eras que aos segundos, pode implicar um afastamento da disciplinaridade, das práticas imediatistas, das prescrições pseudoelucidativas.

Ainda que não passem de inferências sobre a tendência dos caminhos investigativos de Doll Jr. e dos nossos também, é possível constatar que os cinco C contribuem para discussões em dimensões mais universais e, consequentemente, mais teóricas, sobre os currículos, em qualquer etapa da escolaridade e em qualquer disciplina. Contudo, não há como fugir de um caráter transdisciplinar ou até (in)disciplinar (MIGUEL; VILELA; MOURA, 2010).

No início de um novo milênio, somos testemunhas de uma mudança paradigmática do modernismo para o pós-modernismo. Como qualquer período de transição, é difícil nos desligarmos das raízes modernas que ainda envolvem as noções de currículo.

Nesses tempos pós, Doll Jr. contribui para que pensemos no currículo, não como listas de princípios e objetivos, como propunha Tyler, representante da tradicional teoria do currículo, mas sim como ação, fluxo contínuo, experiência de vida, recheado de incertezas e organizações temporais caóticas, muito além das simples e lineares relações estabelecidas entre passado, presente e futuro.

Os currículos requerem pluralidade. Pluralidade de pensamentos, de histórias (não só a história dos vencedores, dos bem-sucedidos, mas também dos vencidos, dos que não têm voz), de ficções (incluindo o exercício de colocar-se no lugar do outro), de conversas, de convivências (para muito além da mera tolerância), de conversões (obtidas após inúmeras discussões e não como aceitação dogmática da verdade do outro), de compreensões e, essencialmente, de transformações.

Quando fala de transformação, Doll Jr. (2002) se refere à John Dewey como um grande visionário das teorias pós-modernas, mesmo vivendo em tempos modernos. Aqui, 
citaremos Paulo Freire que, para nós, também foi outro grande idealista. Para Freire (1996, p. 43):

\begin{abstract}
$\mathrm{O}$ que se coloca à educadora ou ao educador democrático, consciente da impossibilidade da neutralidade da educação, é forjar em si um saber especial, que jamais deve abandonar, saber que motiva e sustenta sua luta: se a educação não pode tudo, alguma coisa fundamental a educação pode. Se a educação não é a chave das transformações sociais, não é também simplesmente reprodutora da ideologia dominante. $\mathrm{O}$ que quero dizer é que a educação nem é uma força imbatível a serviço da transformação da sociedade, porque assim eu queira, nem tampouco é a perpetuação do "status quo" porque o dominante o decrete. O educador e a educadora críticos não podem pensar que, a partir do curso que coordenam ou do seminário que lideram, podem transformar o país. Mas podem demonstrar que é possível mudar. E isto reforça nele ou nela a importância de sua tarefa políticopedagógica.
\end{abstract}

A consciência do poder transformador dos professores, da Matemática, da educação, sobre a realidade que muitas vezes nos é imposta, já seria um passo pequeno, porém fundamental para a construção de uma compreensão mais adequada a respeito da importância dos papeis do currículo de Matemática no ensino médio, tanto sobre as micro, quanto sobre as macrocomunidades.

Esperamos que as considerações de Doll Jr. sobre currículo como currere, como complexidade, como cosmologia, como conversa e como comunidade, bem como as reflexões que trazemos neste artigo, suscitem debates em torno das questões curriculares da Matemática, bem como nos estimule a promover transformações profundas no tradicional discurso curricular vigente no Ensino Médio brasileiro.

\title{
Referências
}

BOWERS, C. A. Educating for an ecologically sustainable culture: rethinking moral education, creativity, intelligence, and other modern orthodoxies. Albany: State University of New York Press, 1995.

CORAZZA, S. M. Diferença pura de um pós-currículo. In: LOPES, A. C.; MACEDO, E. (Ed.). Currículo: detabes contemporâneos. 3. ed. São Paulo: Cortez, 2010.

D’AMBROSIO, U. Transdisciplinaridade. 2. ed. São Paulo: Palas Athena, 1997.

DAVIS, B. Complexity and Education: vital simultaneities. Educational Philosophy and Theory, Oxford, v. 40, n. 1, p. 50-65, fev. 2008.

DAVIS, B.; SIMMT, E. Understanding learning systems: Mathematics Education and Complexity Science. Journal for Research in Mathematics Education, Reston, v. 34, n. 2, p. 137-167, mar. 2003.

DOLL JR., W. E. A post-modern perspective on curriculum. New York: Teachers College Press, 1993. 
DOLL JR., W. E. Currículo: uma perspectiva pós-moderna. Porto Alegre: Artes Médicas, 1997.

DOLL JR., W. E. Ghosts and the Curriculum. In: DOLL JR., W. E.; GOUGH, N. (Ed.). Curriculum visions. New York: Peter Lang, 2002. p. 23-70.

EAGLETON, T. The illusions of postmodernism. Oxford: Blackwell Publishing, 1996.

FREIRE, P. Pedagogia da autonomia: saberes necessários à prática educativa. São Paulo: Paz e Terra, 1996.

LARAIA, R. B. Cultura: um conceito antropológico. 19. ed. Rio de Janeiro: Zahar, 2006.

MIGUEL, A.; VILELA, D. S.; MOURA, A. R. L. Desconstruindo a matemática escolar sob uma perspectiva pós-metafísica de educação. Zetetiké, Campinas, v. 18, p. 129-206, 2010.

MORIN, E. Educação e complexidade: os sete saberes e outros ensaios. 4. ed. São Paulo: Cortez, 2007.

MORIN, E.; CIURANA, E.-R.; MOTTA, R. D. Educar na era planetária: o pensamento complexo como método de aprendizagem no erro e na incerteza humana. São Paulo: Cortez Editora, 2003.

NETO, V. F.; SILVA, M. A. Competências profissionais de professores de Matemática do Ensino Médio valorizadas por uma "boa" escola: a supremacia da cultura da performatividade. Bolema, Rio Claro, v. 27, n. 45, p. 143-164, 2013.

PINAR, W. F.; GRUMET, M. Toward a poor curriculum. Dubuque, IA: Kendall/ Hunt, 1976.

PIRES, C. M. C.; SILVA, M. A. Desenvolvimento curricular em Matemática no Brasil: trajetórias e desafios. Quadrante, Lisboa, v. 20, n. 2, p. 57-80, abr. 2011.

SACRISTÁN, J. G.; PÉREZ-GÓMEZ, Á. I. Compreender e transformar o ensino. 4. ed. Porto Alegre: ArtMed, 1998.

SILVA, M. A. Currículos de Matemática no Ensino Médio: em busca de critérios para escolha e organização de conteúdos. 2009. 249 f. Tese (Doutorado em Educação Matemática) - Pontifícia Universidade Católica de São Paulo, São Paulo, 2009.

SILVA, M. A. Práticas sociais híbridas: contribuições para os estudos curriculares em Educação Matemática. Horizontes, Bragança Paulista, v. 30, n. 2, p. 95-102, jul./dez. 2012.

SILVA, M. A. Contribuições Contemporâneas para as Discussões Curriculares em Educação Matemática: a teoria crítica pós-moderna. Alexandria, Florianópolis, v. 6, n. 1, p. 205-233, abr. 2013.

SILVA, M. A.; PIRES, C. M. C. A riqueza nos currículos de Matemática do Ensino Médio: em busca de critérios para seleção e organização de conteúdos. Zetetiké, Campinas, v. 21, n. 39, p. 19-52, jan./jun. 2013.

SILVA, M. A.; PIRES, C. M. C. Organização curricular da Matemática no Ensino Médio: a recursão como critério. Ciência \& Educação, Bauru, v. 19, n. 2, p. 249-266, jun. 2013.

SILVA, T. T. Documentos de identidade: uma introdução às teorias do currículo. Belo Horizonte: Autêntica, 1999a. 
SILVA, T. T. O currículo como fetiche: a poética e a política do texto curricular. 1. ed. Belo Horizonte: Autêntica, 1999b.

SILVA, T. T. (Org.). Nunca fomos humanos: nos rastros do sujeito. Belo Horizonte: Autêntica, 2001.

SILVA, T. T. O adeus às metanarrativas educacionais. In: SILVA, T. T. (Org.). O sujeito da educação: estudos foucaultianos. 8. ed. Petrópolis: Vozes, 2011. p. 249-260.

SILVA, T. T. Currículo e identidade social: territórios contestados. In: SILVA, T. T. (Org.). Alienígenas na sala de aula: uma introdução aos estudos culturais em educação. 10. ed. Petrópolis: Vozes, 2012. p. 185-201.

TRUEIT, D. Watercourses: from poetic to poietic. In: DOLL JR., W. E. et al. (Org.). Chaos, Complexity, Curriculum, and Culture. New York: Peter Lang, 2005. p. 77-99. 